\title{
Relationships between stem size and branch basal diameter variability in Norway spruce (Picea abies (L.) Karsten) from two regions of France
}

\author{
Michel LOUBÈRE*, Laurent SAINT-ANDRÉ, Jean-Christophe HERVÉ, Geir Isaak VeSTøL \\ Resource, Forest and Wood Research Laboratory, ENGREF-INRA, Nancy, France
}

(Received 3 September 2002; accepted 12 January 2004)

\begin{abstract}
Statistical relationships between branch basal diameter of living whorls, stem size (height and diameter at breast height) and stand parameters (stand age, site class) were analysed in Norway spruce. The first experimental sample used to calibrate a model consisted of 98 trees from young to old stands growing in Lorraine (Eastern part of France). Every second whorl branch basal diameter was measured and a regression model was established for the living branches. Basal diameter variance components were estimated by a non-linear mixed model analysis. Results confirmed the close statistical relationships between branch basal diameter, tree size and stand parameters, whereas covariance analysis revealed significant random fluctuations among whorls and trees. Every third whorl branch basal diameter of 36 Norway spruce trees growing naturally in Midi-Pyrénées was used for the second analysis. Applying the model to these trees showed a good stability of the statistical relationship between the two regions.
\end{abstract}

branch diameter / Norway spruce / wood quality / Lorraine / Midi-Pyrénées

Résumé - Relation entre la taille des tiges et le diamètre basal des branches pour l'épicéa commun (Picea abies (L.) Karsten) de deux régions de France. On a étudié la relation statistique entre le diamètre des branches verticillaires vivantes, la taille de la tige (hauteur et diamètre) et les mesures de peuplement (âge du peuplement, indice de fertilité), chez l'épicéa commun. Pour établir le modèle, 98 arbres ont été échantillonnés en Lorraine. Le diamètre des branches verticillaires a été mesuré tous les deux verticilles. Un modèle de régression a été mis au point. Les composantes de la variance du diamètre basal ont ensuite été estimées, par un modèle mixte non linéaire. On a confirmé pour les branches vertes la forte relation statistique entre le diamètre basal, la taille de la tige et les mesures de peuplement. Cependant, l'analyse de covariance a montré qu'il existait une variation aléatoire entre les verticilles et entre les arbres. Un échantillon de 36 arbres de Midi-Pyrénées, représentatif de la ressource dans cette région a été mesuré tous les trois verticilles. L'application du modèle aux données de Midi-Pyrénées a montré que la relation statistique pouvait être stable d'une région à l'autre.

diamètre des branches / épicéa commun / qualité du bois / Lorraine / Midi-Pyrénées

\section{INTRODUCTION}

Wood quality optimisation consists in finding, for each tree, the best end-use given its wood's properties [7]. At any moment in time a standing resource is the result of tree growth processes driven by genetics, environmental factors and silviculturists. In conifers, with special reference to Norway spruce (Picea abies (L.) Karst., [5]) or Corsican pine (Pinus nigra ssp. Laricio, [26]), crown development was observed to be determined by height growth, giving rise to a tight correlation between knot diameter and easily assessable traits like stem size (stem height and diameter) or stand parameters (age, fertility, density). In
France, such stem and stand measurement data are collected by the National Forest Inventory. By coupling a statistical model to these data, we could obtain an estimation of the knot distribution and dimension for a given forest resource. For conifers, several methods are being tried to achieve this coupling [2,30,31].

Colin [5], sampling in the Vosges in North-eastern France, expressed the branch diameter as a function of branch insertion height, stem size and stand parameters. Daquitaine [8] reported the same equation from South-western France, except that the parameter varied (Fig. 1). Two contradictory conclusions can be drawn from these studies: (i) In spite of the contrasted growth conditions between the two areas, the statistical correlation

\footnotetext{
* Corresponding author: loubere@ nancy.inra.fr
} 


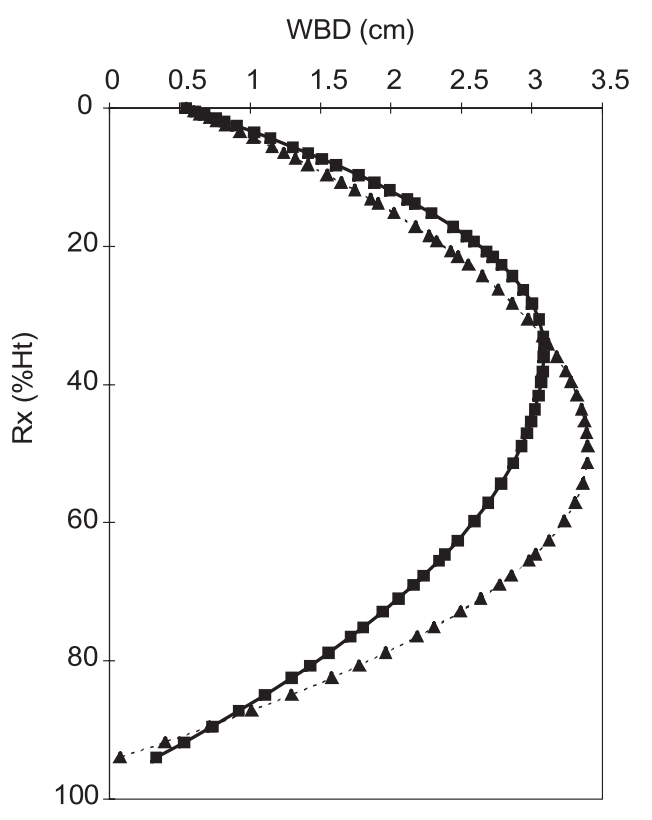

Figure 1. Variation of whorl branch basal diameters (WBD: average of the branch basal diameters within each whorl) with branch insertion height ( $r x$ : branch insertion height expressed as a proportion of tree height, varying from 0 at tree apex to $100 \%$ at tree bottom) as predicted by Colin [5] (—-) and Daquitaine [8] ( - - - - ). Simulated tree characteristics : age $=66$ years $; H t=28.9 \mathrm{~m} ; D B H=41.7 \mathrm{~cm}$.

between branch diameter, stem size and stand parameters seemed qualitatively similar enough to design a common model; (ii) No explanation could be found for the parameter variations, so that a model calibrated for one region can not be used in another one: on the scale of an interregional observation, a significant portion of branch diameter variance would no longer be explained by stem size and stand parameters. This raises a problem if it is intended to turn our experimental wood quality estimation programmes into routinely used tools: for each new region it will be necessary to do a new modelling study. There is a risk that calibration work (expensive and time-consuming) would become prohibitive.

However, before considering any new calibration work, it should be determined whether the problem of interregional parameter variations could have arisen as an artefact of the modelling technique used in the first studies. For example, previous sampling in North-eastern France was done with young trees from average fertility stands. It is not sure that these data permitted observation of the full relationships between branch diameter, stem size and stand parameters. It is also possible that some important predictor has been omitted from the models. Loubère and Colin [24] showed that there were significant differences between the statistical distributions of dead and living branch diameters, especially in old trees. Pooling these two branch populations as in [5] or [8] generated bias, severe difficulties in estimating the residual variance components, and probably concealed some important aspects of the statistical relationships.
This information indicated to us that some improvements could still be made to the previous work. In the following, we have reiterated the experiment reported in Daquitaine [8], with a new modelling approach. Data were collected from the Lorraine region in North-eastern France (same geographic area as Colin [5]). However, we extended the range of stem dimensions and age classes by sampling very old trees. Living and dead branch diameters were treated separately. This paper is devoted to the living branch model. We reused the sample collected by Daquitaine [8] to test the model's performance outside its calibration range.

\section{MATERIALS AND METHODS}

\subsection{Measurements protocol}

Our sampling was designed so as to maximise the range of stem heights, ages and diameters to ensure, as far as possible, stability of the model. Two samples were collected: the first one for the model calibration and the second one for the model evaluation (data provided by Daquitaine [8]).

In the calibration set, we addressed three age classes: young, mature and old stands. As far as possible we explored high and low fertility sites within each age class. In the evaluation set of data, we tried to be representative of the standing resource of the geographical area considered.

The two sampled Geographical areas are displayed in Figure 2. Altitude (Alt, in m) was obtained from The National Geographic Institute maps. They were chosen for their contrasted growth conditions. A close examination of the climatic data computed over the last 10 years (with the equations provided by [1]) revealed that Midi-Pyrénées samples represented a wider range of climatic growth conditions than Lorraine: yearly temperature ranged from $7.4{ }^{\circ} \mathrm{C}$ to $12.45{ }^{\circ} \mathrm{C}\left(8.5\right.$ to $9.4{ }^{\circ} \mathrm{C}$ in Lorraine) and the number of months with an average temperature above $7{ }^{\circ} \mathrm{C}$ varied from 4 to 7 ( 7 in all Lorraine locations).

Figure 2 gives the identifications by which the stands will be referred to in this study. The samples are listed in Table I. The indicated forest districts correspond to different site fertilities and are defined by the National Forest Inventory [17-20]. Taking Lorraine as an example, forest districts range from the highest to the lowest site fertility as follows: "Lorraine Plateau" > "Vosges gréseuses " > "Vosges cristallines" (Tab. I).

Site index was defined as the dominant height (SI: average height of the 100 largest trees per hectare, in m) at age 100 years. It was computed using the equation of Lorieux [23] for Lorraine stands and Daquitaine's equation [8] for Midi-Pyrénées. The number of stems in the stand was recorded (stand density: NHA, in stems/ha). Except for the Lorraine Plateau (Tab. I), where the plantation date was known, stand age (noted Age, in years) was obtained from ring counts on the stumps after tree felling. The stands were assumed to originate from plantation and trees to be even-aged. Stand age was then fixed at the largest value found on stumps. Stem height $(\mathrm{Ht}$, in $\mathrm{m})$ was measured after felling. Diameter at height $1.30 \mathrm{~m}(\mathrm{DBH}$, in $\mathrm{cm})$ was measured over bark to the nearest centimetre. From Ht and DBH, we computed a global stem taper (HD, $\mathrm{cm} / \mathrm{cm}$ ).

Past positions of the terminal shoot along the tree stem were located using the bud scale scars, from the apex down to the butt swell until they could not be identified anymore. Corresponding Growth Units were numbered, starting from 1 at the apex (Growth Unit Number: $G U$ ). In each annual growth unit, we only paid attention to whorl branches: lammas shoots and between-whorl branches were discarded. Branch insertion heights were approximated by the position 
Table I. Sample characteristics. See text for measurements definitions. Refer to Figure 2 for stands location.

\begin{tabular}{|c|c|c|c|c|c|c|c|c|c|c|c|}
\hline \multirow[t]{2}{*}{ Stand } & \multirow{2}{*}{$\begin{array}{l}\text { Forest } \\
\text { district }\end{array}$} & \multirow{2}{*}{$\begin{array}{l}\text { Sampled } \\
\text { trees }\end{array}$} & \multirow{2}{*}{$\begin{array}{l}\text { Site index } \\
\text { (m) }\end{array}$} & \multirow{2}{*}{$\begin{array}{l}\text { Stand density } \\
\text { (stems/ha) }\end{array}$} & \multirow{2}{*}{$\begin{array}{l}\text { Stand age } \\
\text { (years) }\end{array}$} & \multicolumn{3}{|c|}{$H t(\mathrm{~m})$} & \multicolumn{3}{|c|}{$D B H(\mathrm{~cm})$} \\
\hline & & & & & & Average & Minimum & Maximum & Average & Minimum & Maximum \\
\hline 31 & $\begin{array}{l}\text { Vosges } \\
\text { cristallines }\end{array}$ & 18 & 33.0 & 520 & 66 & 25.9 & 22.9 & 28.9 & 35.6 & 24.8 & 45.9 \\
\hline 32 & $\begin{array}{l}\text { Vosges } \\
\text { gréseuses }\end{array}$ & 18 & 36.1 & 510 & 95 & 25.9 & 30.0 & 37.4 & 37.0 & 27.1 & 47.1 \\
\hline 33 & $\begin{array}{l}\text { Vosges } \\
\text { gréseuses }\end{array}$ & 18 & 38.3 & 800 & 68 & 33.3 & 26.8 & 34.2 & 35.2 & 23.9 & 49.3 \\
\hline 34 & $\begin{array}{l}\text { Vosges } \\
\text { cristallines }\end{array}$ & 18 & 31.1 & 520 & 133 & 30.4 & 28.1 & 34.0 & 38.3 & 30.1 & 47.2 \\
\hline 35 & $\begin{array}{l}\text { Plateau } \\
\text { Lorrain }\end{array}$ & 26 & 40.4 & 200 to 10020 & 32 & 15.5 & 9.1 & 20.2 & 16.8 & 6.3 & 33.6 \\
\hline 59 & $\begin{array}{l}\text { Bordure } \\
\text { d'Aubrac }\end{array}$ & 3 & 33.7 & 430 & 58 & 25.8 & 23.7 & 27.5 & 36.8 & 26.7 & 47.1 \\
\hline 60 & $\begin{array}{l}\text { Bordure } \\
\text { d'Aubrac }\end{array}$ & 3 & 39.1 & 1750 & 33 & 12.7 & 9.7 & 16.1 & 18.5 & 13.4 & 25.5 \\
\hline 61 & Ségala & 3 & 42.1 & 890 & 34 & 17.7 & 12.0 & 21.6 & 22.4 & 11.5 & 32.2 \\
\hline 62 & $\begin{array}{c}\text { Basse } \\
\text { châtaigneraie } \\
\text { auvergnate }\end{array}$ & 3 & 51.8 & 1490 & 30 & 17.0 & 13.8 & 19.4 & 18.4 & 11.5 & 26.1 \\
\hline 63 & Lévézou & 3 & 44.5 & 1420 & 20 & 8.8 & 7.4 & 10.4 & 13.4 & 9.9 & 17.2 \\
\hline 64 & $\begin{array}{l}\text { Monts de } \\
\text { Lacaune }\end{array}$ & 3 & 39.9 & 560 & 57 & 26.4 & 25.3 & 28.3 & 42.0 & 33.1 & 56.0 \\
\hline 65 & $\begin{array}{l}\text { Monts de } \\
\text { Lacaune }\end{array}$ & 3 & 36.6 & 450 & 60 & 26.9 & 22.0 & 30.2 & 38.6 & 27.1 & 50.0 \\
\hline 66 & $\begin{array}{l}\text { Monts de } \\
\text { Lacaune }\end{array}$ & 3 & 34.5 & 1080 & 37 & 15.4 & 12.0 & 18.0 & 23.6 & 12.7 & 31.5 \\
\hline 67 & Causses & 3 & 41.2 & 430 & 48 & 24.5 & 21.2 & 27.1 & 32.8 & 20.7 & 42.7 \\
\hline 68 & $\begin{array}{l}\text { Avant- } \\
\text { Causses }\end{array}$ & 3 & 46.1 & 350 & 52 & 30.9 & 28.7 & 34.9 & 42.8 & 31.8 & 55.4 \\
\hline 69 & $\begin{array}{l}\text { Avant- } \\
\text { Causses }\end{array}$ & 5 & 38.3 & 2560 & 25 & 10.9 & 9.0 & 13.4 & 14.9 & 9.2 & 20.4 \\
\hline 70 & $\begin{array}{c}\text { Grands } \\
\text { Causses }\end{array}$ & 3 & 29.0 & 1000 & 26 & 8.1 & 6.6 & 9.9 & 13.9 & 8.0 & 20.7 \\
\hline
\end{tabular}

of the corresponding terminal bud scale scars, so that all branches in a whorl were located at the same distance from the ground $(G U H$, in m). $G U H^{\prime}$ (in m) will refer to the whorl height from the apex. Whorl branch measurements were performed from the tree apex, down to the tree bottom every second whorl for Lorraine trees and every third for Midi-Pyrénées. Branches were considered alive when featuring at least one green needle. Branch basal diameter (noted $\mathrm{Dbg}$ for living branches, in $\mathrm{cm}$ ) was the geometric average of the vertical and horizontal diameters measured outside the branch swell. WBD is the whorl green branches average diameter: $W D B=1 / n \cdot \sum_{i=1}^{n} D b g_{i}$, where $n$ is the number of green branches in the whorl.

\subsection{Stands and trees selection}

\subsubsection{Lorraine trees}

Old and middle-aged trees were sampled from two Vosges localities, in two fertile and two unfertile stands (Tab. I). As far as possible, stand density was kept constant. In each stand, 18 trees were felled, chosen at random from a $100 \mathrm{~m}^{2}$ circular area delimited around the plot centre. We focused on the branch properties, but these trees were also studied for their wood properties: stem transversal section shape [29], knot area ratio [9].

Young trees were sampled from a lowland location $15 \mathrm{~km}$ northeast of Nancy. At the time of the study, and for some practical reasons, we had to sample in an experimental design described in [11-14] (pure and even-aged stand, controlled mating, continuous variation of stand density). Dreyfus [13] showed that this experimental design generated a very high variability of stem dimensions (Tab. I). At each stage of the model construction, the homogeneity of this sample with the oldest trees was checked by examination of the residuals. As no heterogeneity could be detected, those trees were maintained in the Lorraine sample. A study of young trees knots characteristics (knot diameter, sound knot length, dead knot length) paralleled our study of branch basal diameter and was published in [31].

\subsubsection{Midi-Pyrénées}

This sample had been collected by Daquitaine [8], who gave a complete description of the sampling protocol. The idea was to investigate 


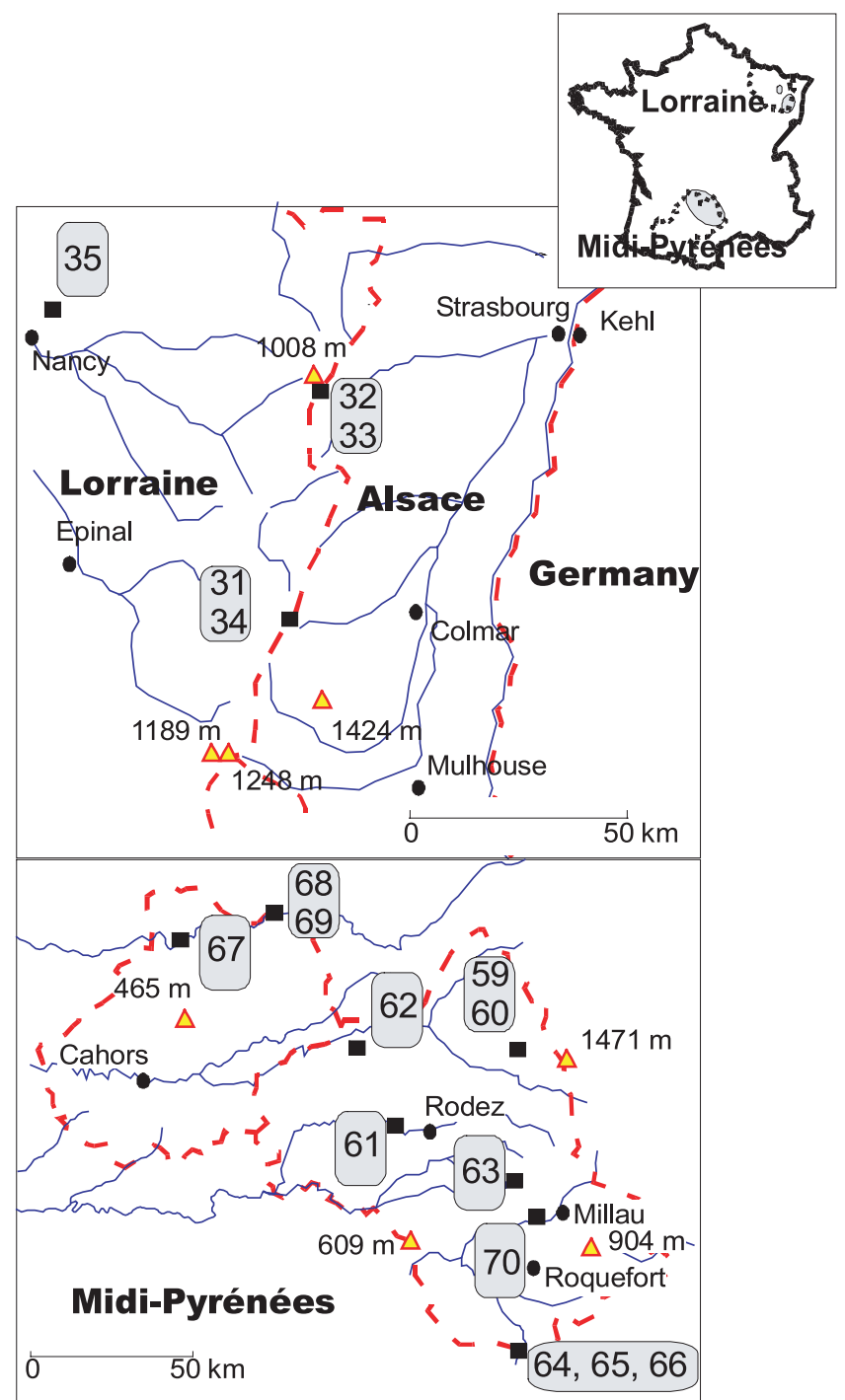

Figure 2. Stands locations; $\mathbf{m}$ : sampled stand location; 35: Stand identification; _ _: State/Province limit; Lorraine: State or Province; $\Delta$ : Altitudinal reference; $\bullet$ : City.

the widest possible range of growth situations, so as to be representative of the Norway spruce ressource in that region. Hence the sampling intensity was reversed, compared to the Lorraine sample. It was lower within trees ( 1 whorl measured every third whorl, instead of every second in Lorraine) and within stands (3 trees in each stand), whereas the number of stands visited was important (12 stands, 8 forest districts, Tab. I).

\subsection{Statistical methods}

When the dead and living whorl branches of a tree are pooled together, branch diameter variance is basically heterogeneous, which has major consequences for the modelling work [24]. An example of the phenomenon is shown in Figure 3 for an old tree crown.

In Figure 3, dead and living branches were plotted together. The evolution of the within-whorl variance along the crown follows a complex pattern. The zone of the bole in which diameters reached a maximum was also the zone where within-whorl variance was the greatest.

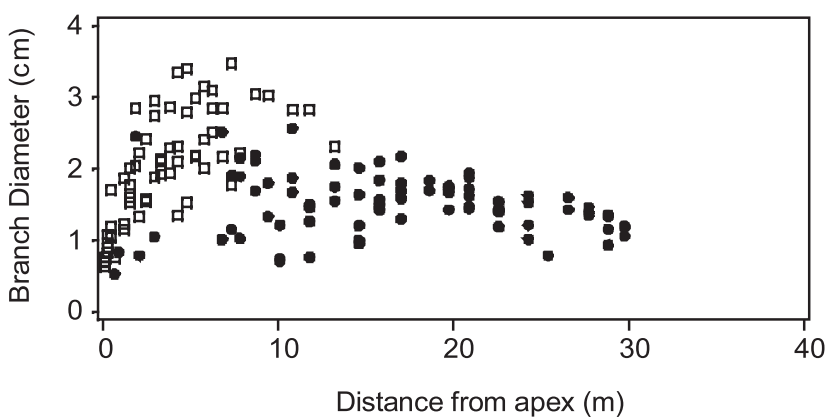

Figure 3. Influence of dead branches on the evolution of branch basal diameter variance with height in the tree, in aged trees. Case of a tree aged 95 years old (Height: $31.6 \mathrm{~m}, D B H: 31.5 \mathrm{~cm}$ ): Dead

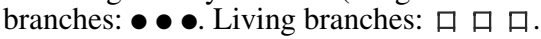

From that zone, within-whorl variance decreased towards the tree apex and towards the butt log. This variance pattern was not statistically simple and constitutes a heavy limitation on the model's robustness. It is caused by four factors:

- In living whorls, the differences between the thickest branch and thinnest one increases as and when the tree grows.

- With tree ageing, living whorls also contained dead thin branches contributing to the inflation of the within-whorl branch diameter variance.

- In dead whorls, an unknown number of branches have been naturally or artificially pruned. The older the tree, the longer the time elapsed between branch death and the moment of study, and so the number of branches that have been pruned is greater. Computing a realistic estimate of dead branch diameter variance therefore seemed unrealistic for old trees.

- It has been shown for Norway spruce that branch lifespan increases with tree age [16]. It was therefore possible that the branches located in the living whorls at the time of the study were actually older than the branches located in the dead whorls. As in a whorl, branch diameter variance increased with whorl age (Fig. 3), and the branch diameter variance in the living crown was larger than in the dead crown.

For living branches, trends are much more identifiable. When moving down the tree, we found that both whorl average diameter and within-whorl variability increased (Fig. 3). Such a variance pattern required only a $\log$ transformation. The models were designed by $\mathrm{Ln}(D b g)$, where $\mathrm{Ln}$ is the natural logarithm.

Lorraine trees were split into a calibration and a validation subsample by randomly allocating nine trees by stands to the calibration subsample. We used a parameter prediction technique. The fitting procedure was iterative:

(i) Finding the best equation for modelling the relationships between branch diameter and branch height within the tree (the tree model).

(ii) Fitting the model tree by tree, so as to obtain an estimate of the parameters for each tree (tree parameters).

(iii) Analysing the relationships between one of the tree parameters, stem size and stand descriptors. We used linear stepwise regression (PROC REG ${ }^{\circledR}$ SAS Institute, 5\% significance level).

(iv) Replacing the studied parameter by the regression equation found in (iii) and restarting the process from (ii) until all tree parameters had been replaced by their expression as functions of stem and stand descriptors.

The model obtained at the end of the process was a non-linear leastsquare model and was referred to as the global model. It was fitted by means of a non-linear least-squares procedure, using a Marquardt convergence algorithm (Proc NLIN ${ }^{\odot}$ SAS Institute). Parameter significance was assessed by comparing the parameters' asymptotic standard error 
to their estimate. A parameter was deleted when its asymptotic standard error exceeded $10 \%$ of the estimated value. An F test based on the RMSE (root mean square error) was also computed to verify that the deletion of the parameter has no major influence on model performance.

A covariance analysis using a mixed models technique was therefore undertaken to estimate the components of the residual variance of the non-linear least-square global model, i.e. the additional sources of variations, once all of the covariates had been taken into account. The global model, built at the previous step, became the covariate part of the covariance model. As it was a non-linear model, we had to linearise it. This was achieved by a Taylor series expansion around 0 for the random effects, since those are supposed to have a 0-centred normal distribution $[22,26]$. For the fixed effects, the model was linearised around the parameter values found in the non-linear least-square step.

\section{RESULTS}

\subsection{Building of the living branches diameters model}

\subsubsection{Selection of the tree model}

Living branch diameters followed very similar trends from one tree to another. A simple exponential model performed the best:

$$
\operatorname{Ln}(D b g)=p-a \cdot e^{-b \cdot G U H^{\prime}}+\varepsilon
$$

where $D b g$ is the living branch diameter $(\mathrm{cm}), G U H^{\prime}$ is branch insertion counted from the stem apex and $p, a, b$ are the parameters to be estimated.

Figure 4 shows the fitting results for five randomly chosen trees (one tree per stand). In most cases, $\operatorname{Ln}(D b g)$ increased asymptotically from the tree apex down to the crown base. In a few cases this increase was linear. The asymptotic pattern was more common in tall and long-crowned trees, while the linear pattern was observed in suppressed short-crowned trees.

Equation (1) can be interpreted as a potential $\operatorname{Ln}(D b g)$ value $p$, reduced by a term depending on the branch distance from the tree apex. $\operatorname{Exp}(p)$ is then the upper limit of $W B D$ distribution. Within the context of wood quality improvement, this parameter is of major importance and corresponded to the maximum achievable whorl average diameter (symbolized as $M A W D$ ). Its average, found for the Lorraine sample, was ( \pm standard deviation) $3.5 \mathrm{~cm}( \pm 1.0 \mathrm{~cm})$. From equation (1), $D b g$ at branch age 0 (top of the tree) is $p-a$, and $b$ is a form parameter. Together with $a, b$ controls the rate at which the model converges towards its asymptote. The exponential term in the log model was necessary to take into account the inflection point found at the top of the trees.

\subsubsection{General model: “Lorraine” model}

The asymptote $p$ was correlated tightly with tree height and stem taper (Fig. 5a, Eq. (2.3)). For $a$, several models were available. The exponential form displayed in Figure $5 b$ and equation (2.4) featured the smallest residual variance and appeared to be a good way to prevent computing of negative values of $a$. But, in Figure 5, it can also be seen that this exponential form was due to a few thin stems from stand 35 . For thicker stems, the relationship was linear. This exponential form should then be confirmed in the future. Parameter $b$ did not vary from one tree to another (Eq. (2.5)). It was therefore fixed to a constant for the whole sample.

The final branch diameter equation obtained is displayed in equation (2.2). Residual standard deviation of equation (2.2) was $0.32 \log$ units $(=1.38 \mathrm{~cm})$. Residual distribution was leftskewed, showing that not all of the heteroscedasticity had been removed by the log transformation. Application to the validation subsample yielded a similar residual standard deviation of $0.31 \log$ units. But it also revealed that the model slightly underestimated branch diameters from stands 31 and 32, while slightly overestimating those from stand 34 (Tab. II). In the case of stand 35 (young trees), the possibility of residual trends with progeny and stand density was investigated and none was found (respectively $p>0.1140$ for the density effect and $p>0.5487$ for the progeny effect).

Branches from a tree can not be considered as independent observation units. We tested the "whorl", "tree" and "stand" effects. Whorl and tree effects were only relevant, yielding the non-linear mixed model displayed in equation (2.1). This equation was fitted to the whole data set. Parameter estimates and test statistics are displayed in Table III. Figure 6 gives an example of the predictions, obtained for one tree of stand 34. A comparison between Figures 4 and 6 revealed the improvement made by adding the random parameters (here the whorl and tree effects, noted respectively $\eta_{w(t)}$ and $\eta_{t}$ in equation (2.1).

$\left\{\begin{array}{l}\operatorname{Ln}\left(D b g_{i j k}\right)=f\left(G U H^{\prime}\right)+\eta_{w(t)}+\eta_{t}+\eta_{i j k} \\ f\left(G U H^{\prime}\right)=p_{k}-a_{k} \cdot \exp \left(-b_{k} \cdot G U H_{j k}^{\prime}\right) \\ p_{k}=\alpha_{1} \cdot H t_{k}-\alpha_{2} \cdot H D_{k}+\alpha_{3} \\ a_{k}=\alpha_{4} \cdot \mathrm{e}^{\alpha_{5} \cdot D B H_{k}} \\ b_{k}=\alpha_{6}\end{array}\right.$

$D b g_{i j k}$ : basal diameter $(\mathrm{cm})$ of the $i$ th branch from the $j$ th whorl of the $k$ th tree.

$G U H_{j k}^{\prime}$ : distance between tree $k$ apex and the whorl $j$ of this tree (in m).

$a_{k}, b_{k}, p_{k}$ : parameters of the tree model (see Eq. (1)).

$\alpha_{1}, \ldots, \alpha_{6}$ : fixed effects parameters to be estimated.

$\eta_{w(t)}, \eta_{t}, \eta_{i j k}$ : random effects parameters to be estimated defined as follow:

- $\eta_{w(t)}=N\left(0, \sigma_{w(t) j k}^{2}\right):$ random parameter associated with the $j$ th whorl from the $k$ th tree.

- $\eta_{t}=N\left(0, \sigma_{t_{k}}^{2}\right):$ random parameter for the $k$ th tree.

- $\eta_{i j k}=N\left(0, \sigma_{\varepsilon}^{2}\right)$ : random parameter for the $i$ th branch of $j$ th whorl in the $k$ th tree.

\subsection{Assessment of the model stability outside of its calibration range}

Equation (2.1) was applied to the evaluation sample. With a model containing random terms, it is not possible to compute residuals for each individual branch. We therefore checked the 

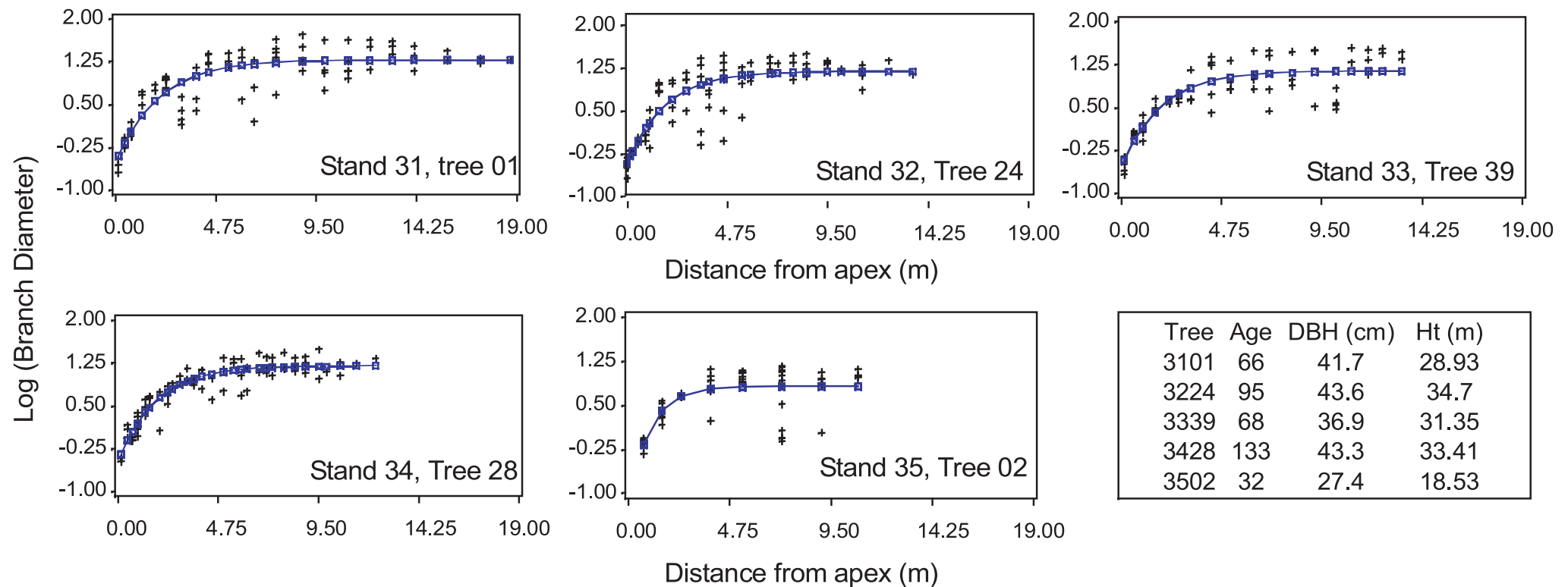

\begin{tabular}{|cccc|}
\hline Tree & Age & DBH $(\mathrm{cm})$ & $\mathrm{Ht}(\mathrm{m})$ \\
3101 & 66 & 41.7 & 28.93 \\
3224 & 95 & 43.6 & 34.7 \\
3339 & 68 & 36.9 & 31.35 \\
3428 & 133 & 43.3 & 33.41 \\
3502 & 32 & 27.4 & 18.53 \\
\hline
\end{tabular}

Distance from apex $(\mathrm{m})$

Figure 4. Examples of equation (1) fittings. Results are illustrated by one tree randomly chosen in each stand of the calibration sample. Branch diameter values are log transformed. Natural logs were used. ++ +: Observed branch diameters; 7 F: model predictions.
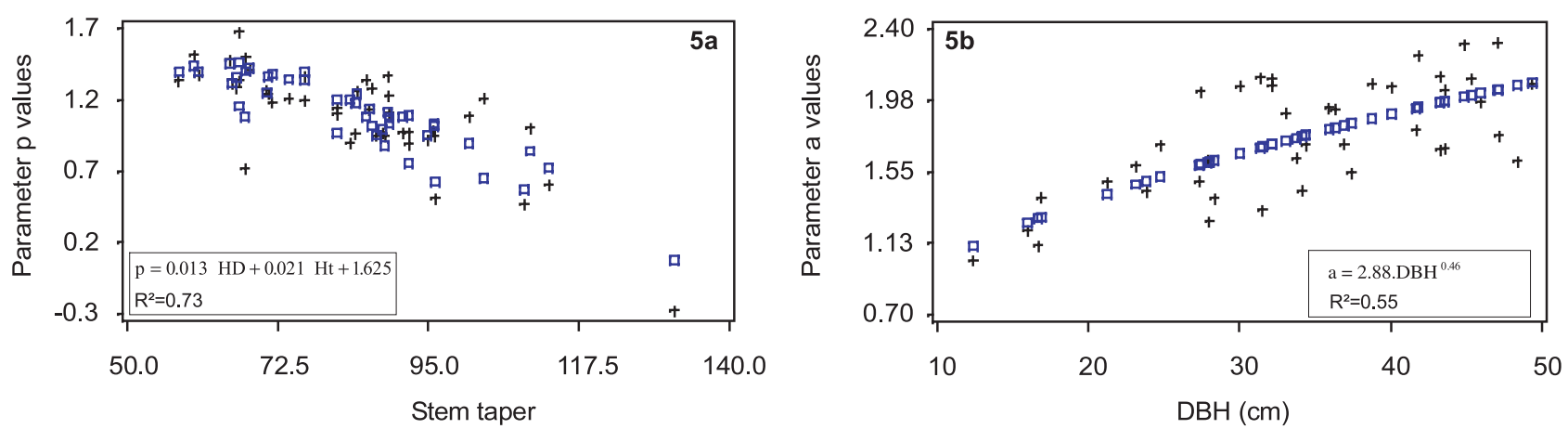

Figure 5. Equation (1) parameters expressed as functions of stem height and diameter. ++ †: Value of parameters a and p found by fitting equation (1) to each tree; $\square$ 口 $\square$ : values computed with the function, relating a and $\mathrm{p}$ to stem height and diameter, displayed in the plot. 
Table II. Whorl branches average diameter $(W D B)$ : residual statistics for each stand of the Lorraine sample. Predicted values computed with equation (2.2). Calibration sample: residuals of the fitting of the least-square model (Eq. 2.2). Validation sample : Residuals from the applications of equation (2.2) to validation trees. All residuals statistics are expressed in log units.

\begin{tabular}{|c|c|c|c|c|c|c|c|c|c|c|}
\hline \multirow[t]{2}{*}{ Stand } & \multicolumn{5}{|c|}{ Calibration sample } & \multicolumn{5}{|c|}{ Validation sample } \\
\hline & $\begin{array}{l}\text { Number of } \\
\text { branches }\end{array}$ & Mean & $\begin{array}{l}\text { Standard } \\
\text { deviation }\end{array}$ & $\mathrm{T}$ & $p>|\mathrm{T}|$ & $\begin{array}{c}\text { Number of } \\
\text { branches }\end{array}$ & Mean & $\begin{array}{l}\text { Standard } \\
\text { deviation }\end{array}$ & $\mathrm{T}$ & $p>|\mathrm{T}|$ \\
\hline 31 & 599 & $1.34 \cdot 10^{-2}$ & 0.30 & 1.07 & NS & 577 & $6.56 \cdot 10^{-2}$ & 0.30 & 5.17 & 0.0001 \\
\hline 32 & 634 & $9.94 \cdot 10^{-3}$ & 0.30 & 0.85 & NS & 567 & $3.62 \cdot 10^{-2}$ & 0.31 & 2.75 & 0.0061 \\
\hline 33 & 575 & $-9.08 \cdot 10^{-3}$ & 0.34 & -0.64 & NS & 557 & $-1.98 \cdot 10^{-2}$ & 0.29 & -1.60 & NS \\
\hline 34 & 508 & $-2.45 \cdot 10^{-2}$ & 0.36 & -1.54 & NS & 612 & $-4.34 \cdot 10^{-2}$ & 0.38 & -2.82 & 0.0050 \\
\hline 35 & 365 & $9.16 \cdot 10^{-3}$ & 0.31 & 0.56 & NS & 679 & $7.23 \cdot 10^{-3}$ & 0.26 & 0.72 & NS \\
\hline Overall & 2681 & $-5.36 \cdot 10^{-10}$ & 0.32 & 0.00 & NS & 2992 & $8.60 \cdot 10^{-3}$ & 0.31 & 1.50 & NS \\
\hline
\end{tabular}

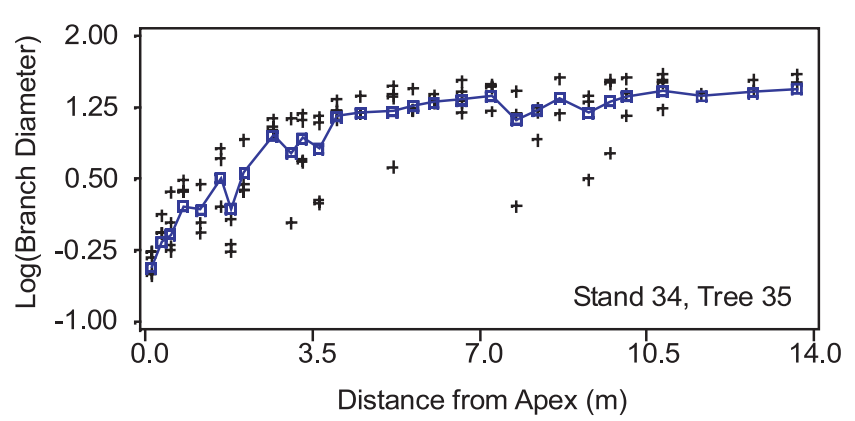

Figure 6. Fitting of equation (2). Example of the predictions for one tree chosen from the oldest stand (133 years old). Branch diameters are $\log$ transformed. ++ +: Observed values; predictions.

accuracy of the whorl average branch diameter estimates $(W D B$ obtained from (2.2) and represented as a solid line in Fig. 7) and of the predicted variance around this average (broken lines in Fig. 7). Lower and upper limits of the diameter distribution were calculated as follows (example of the upper limit $D b_{\max }$ ): $D b_{\text {Max }}=W D b+1 \sigma_{w(t)}+1 \sigma_{t}+1 \sigma \varepsilon, W D B$ : whorl green branch average diameter computed using the fixed effects part of equation (2); $\sigma_{w(t)}$ : standard deviation of the whorl effect; $\sigma_{t}$ : standard deviation of the tree effect; $\sigma_{\varepsilon}$ : standard deviation of the residuals. Computation was similar for the lower limit $\left(D b_{\text {Max }}=W D b-1 \sigma_{w(t)}-1 \sigma_{t}-1 \sigma_{\varepsilon}\right)$. Values in Figure 7 were transformed back from log. The young tree represents an age class outside the calibration range. The old tree (52 years old), on the other hand, was closer to the age classes represented in the calibration sample. For both trees, WBD predictions were quite accurate. But the accuracy of the diameter variability prediction decreased for the young trees. This indicated that the model's trends with age should be controlled.

The statistical relationship between branch basal diameter and stem dimensions is included in the statistical functions that relate the tree parameters $a_{k}, b_{k}$ and $p_{k}$ to the stem and stand parameters (Eqs. (2.3), (2.4) and (2.5)). The accuracy of these functions was also assessed with the evaluation sample. We fitted equation (1) to each tree $\mathrm{k}$ and $\operatorname{got}\left(a_{k}, b_{k}, p_{k}\right)$ triplets ( $x$ values in Fig. 8). These were compared to the $\left(\hat{a}_{k}\right.$, $\left.\hat{b}_{k}, \hat{p}_{k}\right)$ triplets computed with equations $(2.3),(2.4)$ and $(2.5)$
Table III. Lorraine model parameters estimates and test statistics (model definition in Eq. (2.1)). $\alpha_{1}, \mathrm{~K}, \alpha_{6}$ : fixed effects parameters. $\eta_{w(t)}$ : whorl random effect parameter. $\eta_{t}$ : tree random effect parameter.

\begin{tabular}{lcccc}
\hline \multicolumn{5}{c}{ Fixed effects parameters } \\
\hline Parameter & Estimation & $\begin{array}{l}\text { Standard- } \\
\text { deviation }\end{array}$ & $t$ & $p>|t|$ \\
\hline$\alpha_{1}$ & $2.49 \cdot 10^{-2}$ & $0.26 \cdot 10^{-2}$ & 9.77 & 0.0001 \\
$\alpha_{2}$ & $-7.55 \cdot 10^{-3}$ & $1.00 \cdot 10^{-3}$ & -7.53 & 0.0001 \\
$\alpha_{3}$ & 1.03 & 0.11 & 9.09 & 0.0001 \\
$\alpha_{4}$ & -1.18 & 0.09 & -12.81 & 0.0001 \\
$\alpha_{5}$ & 1.13 & 0.20 & 5.56 & 0.0001 \\
$\alpha_{6}$ & \multicolumn{5}{c}{ Random effects parameters } \\
\hline \multicolumn{5}{c}{ Standard- } \\
\hline Parameter & Estimation & deviation & \\
\hline$\eta_{w(t)}$ & $2.67 \cdot 10^{-2}$ & $0.27 \cdot 10^{-2}$ & 9.97 & 0.0001 \\
$\eta_{t}$ & $4.16 \cdot 10^{-3}$ & $1.84 \cdot 10^{-3}$ & 2.80 & 0.0001 \\
Residual & & & 30.98 & 0.0001 \\
\hline
\end{tabular}

( $y$ values in Fig. 8). $a_{k}, b_{k}$ and $p_{k}$ seemed quite accurately predicted even if a few trees, featuring chaotic variations of their branch diameters, departed from the general trends. $b_{k}$ 's obtained from the fitting of equation (1) featured a mean ( \pm standard deviation) of $0.812( \pm 1.02)$, which is not significantly different from the Lorraine value.

\section{DISCUSSION}

\subsection{The model}

In their study, Colin and Houllier [6] pooled data from dead and living branches. Their conclusion was that distance from the stem apex, stem height and $\mathrm{DBH}$ were the main predictors of branch basal diameter. Other possible variation sources such as provenance effects or competition stress could be neglected. Our results strongly support these hypotheses. In equation (2.1), no independent variable was found to be significant, apart from 


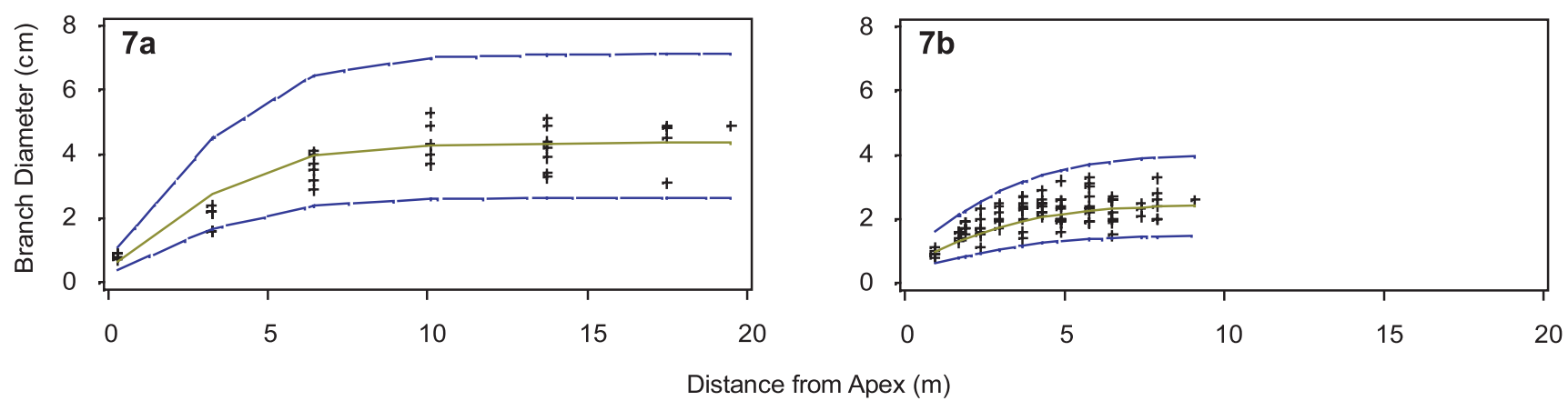

Figure 7. Application of the general "Lorraine" model (Eqs. (2.1)-(2.5)) to Southern France trees. Predicted values back-transformed from log. Two contrasted examples: (a) old tree (stand 68, 52 years old); (b) young tree (stand 69, 25 years old). $+++:$ measured branch diameters, predicted average branch diameter, - - - predicted average branch diameter \pm 1 standard deviation.
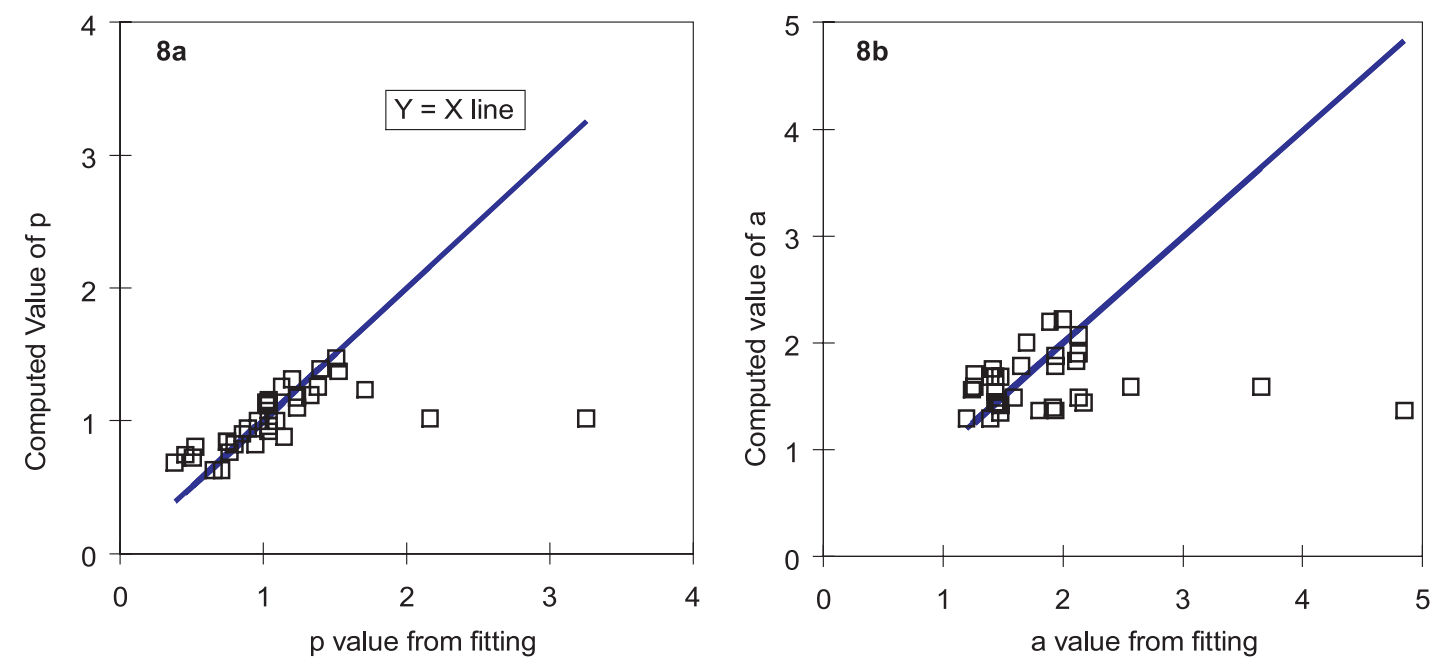

Figure 8. Test of the validity of the relationships between tree parameters (parameters $a, p$ in Eqs. (2.3) and (2.4)), stem height and diameter. Horizontal axis: values of $a, p$ obtained by a fit of equation (1) to the data of each tree of the Midi-Pyrénées sample. Vertical axis: $a$ and $b$ values computed with equations (2.3) and (2.4).

stem height and diameter. Stand parameters like site index and stand density did not enter the model. But, as the stand parameters control the tree height and radial growth, the model is still able to reproduce the effects of their variation. To show this, we computed the maximum achievable branch diameter of trees in various density modalities $(M A W D=\operatorname{Exp}(p), p$ : intercept parameter of equation (1), predicted by (2.3)). Stem height and $D B H$ were extracted from Décourt [10]. They were chosen to represent the average tree of the highest and the lowest fertility classes in the two regions investigated here: Lorraine (solid lines labelled "Northeastern France" in Fig. 9) and MidiPyrénées (broken lines labelled "Massif Central" in Fig. 9). A minimum value of $M A W D$ was achieved around 2000 stems/ha. For lower stand densities, a sharp increase in $M A W D$ was obtained. In high stand densities a small unexpected increase was also found. This trend may prove to be a slight discrepancy in the model caused by a small increase in MAWD estimated values in stand 35 (calibration sample, young trees), from $2000 \mathrm{stems} / \mathrm{ha}$ to $4000 \mathrm{stems} / \mathrm{ha}$. At a given stand density, the variation with site index was small in Northeastern France, which corresponded to the situation in our data (for all the Lorraine trees, $M A W D$ standard deviation was only $1 \mathrm{~cm}$ ). For Massif Central trees, the variations with site index were larger and the highest fertility class featured the thickest branches.

In Colin [6], most of branch diameter variance was explained by a non-linear least-square model including stem and crown dimensions. Here the situation was different. Even once stem dimensions have been included in the model, significant random fluctuations were observed. They were expressed by the random terms in equation( 2.1): "tree effect" (parameter $\eta_{t}$ ), "whorl effect" (parameter $\left.\eta_{w(t)}\right)$. In our context, where data were not independent observations, the presence of a "tree effect" was realistic. Our data did not allow us to offer any hypothesis about the nature of this tree effect. It may be of genetic origin, or could also have been caused by the tree's physiological status: competitive stresses can change the assimilate partitioning between the crown and the stem [21]. 


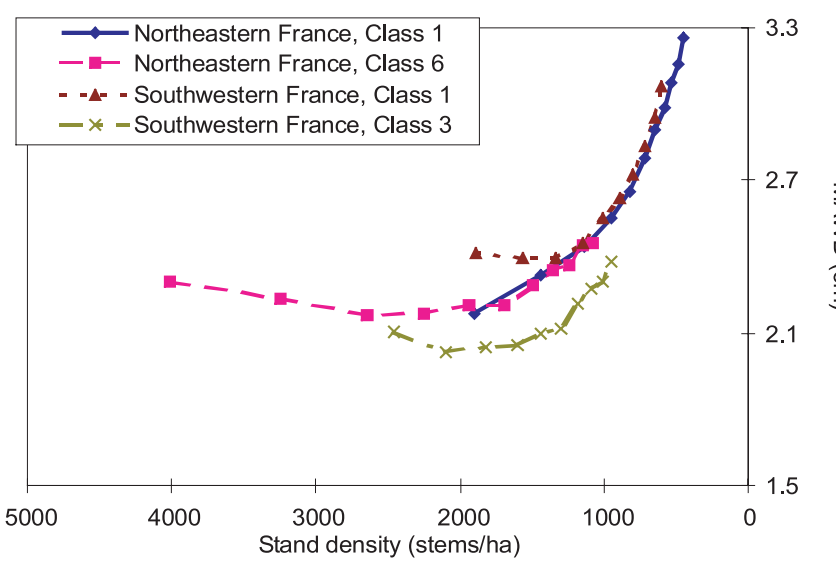

Figure 9. Simulation of the effects of varying stand density and site class on maximum achievable branch diameter $(M A W D=\operatorname{Exp}(p)$, $p$ computed with Eq. (2.3)). Tree heights and DBH described the average tree of Décourt [10] for the lowest and highest fertility classes of Northeastern and Southwestern France.

More questions were raised by the existence of a whorl effect showing the existence of significant whorl-to-whorl variation of branch diameter: in the most extreme cases, all the branches of a whorl could be smaller or thicker than in the whorls under or above it. These whorl-to-whorl fluctuations were observed in both calibration and evaluation samples. An illustration of this is displayed in Figure 10, which features data of an old tree (stand 34, age 133 years, $\mathrm{SI}=31.1 \mathrm{~m}$ ).

Two ideas (microclimate and year effects) may be emphasized and could have triggered this whorl effect in the model:

- Influence from the whorl's local environment: competing neighbour branches or gaps modify the quantity of available light in a given whorl and may therefore significantly enhance or reduce branch growth in this whorl. But as indicated in Figure 10, whorl branch tips pointed towards sometimes very different azimuths. Microclimate may certainly have enhanced or reduced the growth of some of the branches $(G U 22$ in Fig. 10. For this growth unit, The difference between the whorl thickest and thinnest branch was important. We indicated the location of the whorl thickest branch by an asterisk).

- Year effect: environmental or ecophysiological conditions may have influenced branch morphogenesis or spraying, so that potential growth of all the branches in the whorl was definitively reduced or enhanced, compared to the branches produced the year before or after $(G U 14,28$ or 30 in Fig. 10 where branch growth seems to have been seriously reduced or enhanced for all the branches). Ribeyrolles [28] showed that the stresses endured by a tree could affect the branches as soon as during their morphogenesis. Examining branch morphological characters, like the occurrence of plagiotropy, he established that branches from trees enduring severe competitive stresses seemed "physiologically older", even in their first year, than those from dominant trees.

The random "branch effect" $\left(\eta_{i j k}\right.$ in Eq. (2)) suggests that a given branch would be thicker or thinner than the predicted average for its whorl, because its growth would have been

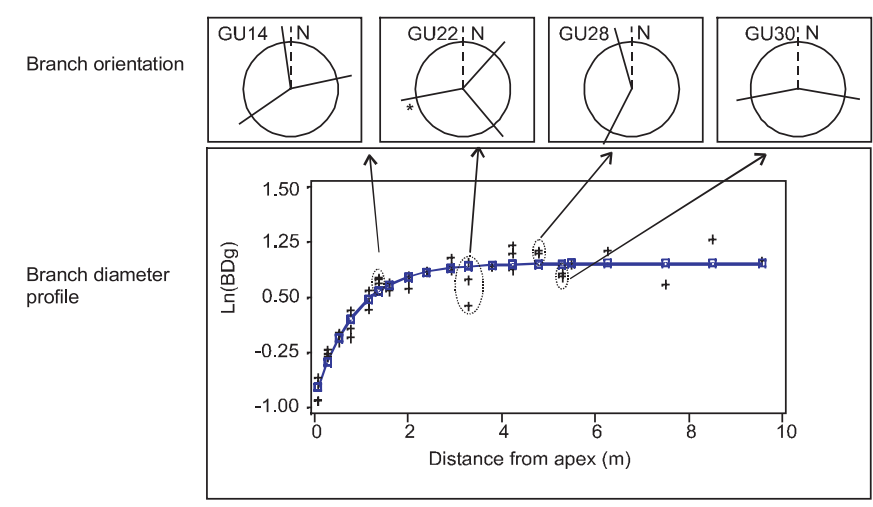

Figure 10. Some examples of whorl effects. Case of a tree from stand 34 (age $=133$ years, SI $=31.10 \mathrm{~m})$. Fitting of equation (1). Disks above the plot indicate whorl branches orientations. +++ : observed values; Direction of the North. : reference line. __ branch insertion.

enhanced or reduced. This looks like the positive feedback in branch growth demonstrated by means of mechanical models [15]. For example, a positive feedback within a whorl would mean that the difference in annual year radial increments between the thickest and thinnest branch would increase all through the branch life. Such segregation of the whorl branches into several diameter classes was observed quite systematically in old trees. This suggests the possibility of a competition between the branches within a whorl (one-sided competition bringing a separation of the studied character into a multimodal distribution [4]), but this point has to be verified by studying the branch radial increment rather than the cumulated diameter.

\subsection{Does there exist a maximum value of branch diameter?}

In Vosges old mountains trees, the absolute lack of a decreasing trend in the branch diameter profile (as shown in Fig. 4) suggested that there would exist a maximal value of branch diameter: the figure $M A W D=\mathrm{e}^{P}$ derived from equation (1) and computed with (2.3), would be the largest value of $W B D$ produced by the tree in its life. As most of the Vosges trees featured asymptotic increase of branches basal diameter along their crown, it seemed that they were old enough to have reached the point where they could not produce any thicker branches. Similar asymptotic within-crown diameter trends were found in other conifer species like Pinus sylvestris [25] and Pinus nigra ssp. laricio [26]. Here above, we formulated an interpretation of Norway Spruce crown development explaining how a branch could grow thicker than another. We can now complete this interpretation, by evaluating where the thickest branches should be inserted in the tree crown, according to our results. In the following, the terms "young", "middle-aged" and "old" refer to the height growth curve (exponential growth, reduced height growth, asymptote of the height growth curve):

- In young trees, the thickest branches are found in the lowest part of the crown because, all of the tree branches are actively growing. The diameter profile features no asymptote. Variability inside the whorls is small at all heights in the crown. 
- In middle-aged trees, whorls containing the thickest branches are found in the upper crown (upper half, or upper third) where within-whorl diameter variability is maximised. Under these big branches are thick branches that have achieved their maximal diameter and are now turning into declining branches. This zone constitutes in most cases the asymptote of the diameter profile (Fig. 4). In the evaluation sample, linear withintree diameter profiles were also found in the short-crowned trees. We suppose that in short-crowned trees, which are often suppressed trees, branches may decline before achieving their maximal diameter.

- In old trees, the evolution of branches along the crown is asymptotic most of the time. The linear pattern disappears for two reasons: (i) the maximum achievable branch diameter has been reached and the trees are not able to produce any thicker branches; (ii) Most of the trees remaining in the stand are dominant or codominant. Short-crowned trees have been eliminated and competitive interactions are assumed to have stabilised.

A verification is needed for old trees. Old Norway spruces may reiterate. Reiteration is likely to confuse the described patterns of branch growth. As we had no information, concerning this point, we were not able to verify the impact of this phenomenon.

\subsection{Difference between regions}

As noted in the Introduction, we tried to reproduce the experiments carried out by Colin [6] and Daquitaine [8]: to fit the model to Lorraine trees and to try to predict branch diameter of the Midi-Pyrénées sample. In our case we changed the range of stem height, $D B H$ and stand age explored and the modelling strategy. We observed that when dead and living branches were pooled, the Lorraine model had to be recalibrated [8]. In contrast, a good predictive accuracy was reached by the model addressing only living branch diameters. We did not need to produce a distinct version of our model for the Midi-Pyrénées sample. This suggests that the difference between those regions should be sought in dead branches and in mortality processes. It should also be noticed that only the variables relating to stem size ( $H t, D B H$ and $H D$ ) were selected in equation (2.1). When dead and living branches were pooled, models also include site index [24], a stand variable, and crown base [5, 24], a variable clearly referring to branch mortality. A symmetrical configuration was found for knot diameter in Swedish Scots pines [2]: knot diameter correlated with tree variables for knots inside the living crown and with site index (a stand variable) for the knots below the living crown. These results should be put in perspective with ecophysiological work on branch death that shows its dependence on light transmission through the canopy [3], and hence on stand structure. Thus, branch growth would be related to stem growth, whereas branch death processes would be influenced by stand variables: to predict green branch diameter it is only necessary to know stem size, while prediction of dead branch diameter requires the inclusion of information about the stand structure.

On the other hand, some limit of our approach must be drawn. Niinemets and Lukjanova [27] showed how site index could modify the correlation between branch length growth and leader growth. For branch elongation, high-fertility grown trees can react to changes in irradiance, while trees limited by the nitrogen supply could not. Thus, the statistical relationships between branch and stem leader elongation completely differed between high and low fertility stands. This suggest either that Norway spruce behaves differently than Scots pine or that we have missed some fertility or stand effects. Northeastern France Site fertilities rate from site class 1 , the highest, to site class 5 , the lowest [10]. Orienting our modelling approach towards tall and old trees, led us to privilege average and high fertility classes (site class 3 to 1 ) and to discard lower fertility classes. The fertility gradient in the calibration sample may be badly represented, so that fertility effects as in [27] did not appear significant in our model.

\subsection{Which sampling strategy for building robust models?}

As pointed out in the Introduction, earlier work on Norway spruce branch diameter produced models with poor extrapolation abilities. We have tried to find the reasons for this behaviour, by questioning two aspects of the modelling work: the statistical method and the sampling method. We have discussed the statistical problem above. But our results also suggest some comments concerning the sampling strategy. In building their model, Colin and Houllier [6] used a sample balanced for young trees. Here, we noticed, that the asymptotic variation of green branch diameter, from which $M A W D$ could be computed, existed mainly in the old and/or tall Vosges trees. It was rarer in the young ones of stand 35 . This shows the need to explore the whole stem size gradient if we want to build more stable relationships between branchiness parameters, stem and stand descriptors. In this regard, our calibration sample balanced for old and tall trees should raise a symmetrical problem, compared to Colin and Houllier [6].

If we want to enlarge the age and fertility variability in our samples, we must consider the problem of the sampling effort. The Lorraine model (Eq. (2)) was made out of data from only 9 trees in each stand. In spite of this small number of trees, it proved good extrapolation abilities. This suggests that representing the age and fertility gradients should be the major concern of future samplings. The ideal number of trees to be sampled in a stand remains to be determined. But, it seems that, provided age and fertility gradients are well accounted for in the sample, it would not be necessary to apply an important sampling effort inside the stands, making it feasible to consider a large number of stands.

\section{CONCLUSION}

Midi-Pyrénées had been chosen because it featured growth conditions and silvilcultural practices contrasting with Lorraine. The stability of the "green branch basal diameter-stem size" relationships found in this study let us with good hopes for building empirical models robust at a multi-regional scale, but also with two types of questions. Firstly, the stability of the "green branch basal diameter-stem size relationship" should be confirmed by observing phenomena at a finer scale than tree and stand scale. Secondly, for the moment our simulated tree was only given a green crown, whereas our objective was describing the full branchiness in order to meet wood quality simulators 
requirements. If we want to reconstruct the part of the crown under the first living branch, it is needed to better characterize the patterns of crown recession and branch mortality. Our next works, will then be oriented towards the description of mortality effects, i.e. branch population structure: where do dead branches lie in the tree and the stand? Can we find some predictor, susceptible of being used with the kind of data we handle, that could refine the prediction of this structure?

Acknowledgments: A great number of people were involved in that work. Clinal working area: Frédéric Bernier, Francis Colin, Michael Drexhage, Michel Loubère, Geir I. Vestøl, Léon Wehrlen. Vosges working area (thanks to all of those who helped the authors in the Vosges, thus depriving themselves of seeing a single sun ray for more than one month!): Thierry Constant, Renaud Daquitaine, Christine Deleuze, Marc Doidy, Pierre Gelhaye, Florence Grandemange, Edith Guilley, Christian Herbé, Jean-Christophe Hervé, Claude Houssement, Gilles Le Moguédec, Michel Loubère, André (Dédé) Perrin, Jean Perrin, Pierre (Pierrot) Michel, Nathalie Morel, Gérard Nepveu, Laurent Saint-André, Geir I. Vestøl. Aveyron working area: René Canta, Renaud Daquitaine, Daniel Rittié, and with great diligence from the people from ONF Aveyron. Vosges and Clinal samples were entirely financed by a grant from UE (contract EC-FAIR STUD CT 96-015).

\section{REFERENCES}

[1] Benichou P., Le Breton O., Prise en compte de la topographie pour la cartographie des champs pluviométriques statistiques, La Météorologie 19 (1987) 1-14.

[2] Björklund L., The interior knot structure of Pinus Sylvestris stems, Scand. J. For. Res. 12 (1997) 403-412.

[3] Bosc A., EMILION, a tree functional-structural model: presentation and first application to the analysis of branch carbon balance, Ann. For. Sci. 57 (2000) 555-569.

[4] Cannell M.G.R., Grace J., Competition for light: detection, measurement and quantification, Can. J. For. Res. 23 (1993) 1969-1979.

[5] Colin F., Analyse et modélisation de la branchaison de l'épicéa commun en vue de prédire la qualité de la ressource, Ph.D. report, ENGREF-INRA, 1992.

[6] Colin F., Houllier F., Branchiness of Norway spruce in Norteastern France: modeling vertical trends in maximum nodal branch size, Ann. Sci. For. 48 (1991) 679-693.

[7] Cown D.J., Corewood (juvenile wood) in Pinus radiata, N. Z. J. For. S. 22 (1992) 87-95.

[8] Daquitaine R., Contribution à la validation des modèles disponibles pour l'évaluation de la qualité du bois d'une ressource forestière existante. Application à l'épicéa commun (Picea abies (L.) Karst.), DEA Modélisation et analyse des systèmes biologiques, INRA Nancy, Wood Quality Research Team, 1995.

[9] Daquitaine R., Saint-André L., Lanvin J.D., Leban J.M., Project Report "Improved Spruce Timber Utilisation". Task A4: Conversion, simulation and optimization. Final Report of subtask A4.1, Simulation of Board quality distribution and validation, EC-FAIR CT96-015, 1999.

[10] Décourt N., Tables de production provisoires pour l'épicéa commun dans le nord-est de la France, Ann. Sci. For. 29 (1972) 49-65.

[11] Deleuze C., Pour une dendrométrie fonctionnelle : essai sur l'intégration de connaissances écophysiologiques dans les modèles de production ligneuse, Ph.D. report, Université Claude Bernard Lyon I, Lyon, France, 1996.
[12] Deleuze C., Blaudez D., Hervé J.-C., Ajustement d'un modèle hauteur-circonférence pour l'épicéa commun. Effet de la densité, Ann. Sci. For. 53 (1996) 93-111.

[13] Dreyfus P., Compétition et croissance dans de jeunes peuplements résineux. Aspects biologiques, écologiques et sylvicoles, Ph.D. report, Aix-Marseille University, Aix-en-Provence, France, 1988.

[14] Dreyfus P., Interaction génotype, densité et compétition dans un dispositif clinal d'épicéas communs, Ann. Sci. For. 47 (1990) 1-16.

[15] Ford R., Ford E.D., Structure and basic equations of a simulator for branch growth in the Pinaceae, J. Theor. Biol. 146 (1990) 1-13.

[16] Gava M., Durata existentei ramurilor principale la molid si mersul cresterii lor în grossime (Norway Spruce whorl branches lifespan and the process of radial growth), Revista padurilor 88 (1973) 531533.

[17] Inventaire Forestier National, Département du Lot, Résultats du $2^{\mathrm{e}}$ inventaire, Vol. I, Ministère de l'Agriculture, 1980.

[18] Inventaire Forestier National, Département de Meurthe-et-Moselle, Résultat du $2^{\mathrm{e}}$ Inventaire, Ministère de l'Agriculture, 1980.

[19] Inventaire Forestier National, Département de l'Aveyron, Résultat du $2^{\mathrm{e}}$ Inventaire, Vol. I, Ministère de l'Agriculture, 1980.

[20] Inventaire Forestier National, Département des Vosges, Résultats du $3^{\mathrm{e}}$ inventaire, Ministère de l'Agriculture, 1992.

[21] Kellomäki S., A model for the relationships between branch number and biomass in Pinus sylvestris crowns. Effect of crown shape and stand density on branch and stem biomass, Scand. J. For. Res. 1 (1986) 455-472.

[22] Littell R.C., Milliken G.A., Stroup W.W., Wolfinger R.D., SAS System for mixed models, SAS Institute Inc, Cary, NC, USA, 1996.

[23] Lorieux M., Essai de modélisation de la croissance de l'épicéa commun du nord-est de la France à partir des données de l'Inventaire Forestier National, DEA Report, Université Claude Bernard Lyon I, CNRS URA 243, Lyon, France, 1990.

[24] Loubère M., Colin F., Simulation of the branchiness on the basis of standard tree measurements, Report, Contract EC-FAIR CT96-015, subtask A2.1, INRA Nancy, 1999, pp. 43-66.

[25] Mäkinen H., Effect of intertree competition on branch characteristics of Pinus sylvestris families, Scand. J. For. Res. 11 (1996) 129136.

[26] Méredieu C., Colin F., Hervé J.C., Modelling branchines of Corsican pine with mixed-effects models (Pinus nigra Arnol ssp. laricio (Poiret) Maire), Ann. Sci. For. 55 (1998) 359-374.

[27] Niinemets Ü., Lukjanova A., Needle longevity, shoot growth and branching frequency in relation to site fertility and within-canopy light conditions in Pinus sylvestris, Ann. For. Sci. 60 (2003) 195208.

[28] Ribeyrolles L., Effets de la densité de plantation sur la croissance, la ramification et l'architecture d'une provenance d'épicéa commun (Picea abies (L.) Karsten), DEA Report, INRA, Wood Quality Research Team, Nancy, France, 1993.

[29] Saint-André L., Modélisation tridimensionnelle des profils de largeur de cerne dans un billon d'épicéa commun (Picea abies Karst.) compte tenu de la mesure de son enveloppe externe et des caractéristiques dendrométriques usuelles de l'arbre d'origine, Ph.D. ENGREF Nancy - INRA Nancy, Wood Quality Research Team, Nancy, France, 1998, 215 p.

[30] Salas-Gonzáles R., Houllier F., Lemoine B., Pignard G., Forecasting wood resources on the basis of National Forest Inventory data Application to Pinus pinaster Ait. in southwestern France, Ann. For. Sci. 58 (2001) 785-802.

[31] Vestøl G.I., Colin F., Loubère M., Influence of progeny and initial stand density on the relationship between diameter at breast height and knot diameter in Picea abies, Scand. J. For. Res. 14 (1999) $470-480$. 